\title{
Músicas escénicas en el archivo INET
}

\section{Malena Soledad Graciosi \\ Profesional independiente en música escénica (MUX) \\ malena.graciosi@gmail.com}

Fecha de recepción: 30/08/2021. Fecha de aceptación: 27/09/2021

\section{Resumen}

En el marco de la Beca Activar Patrimonio 2021, se solicitó consultar algunas colecciones del acervo del Instituto Nacional de Estudios de Teatro (INET) para conocer materiales en distintos soportes que permitan analizar las características del plano sonoro y las músicas espectaculares que han tenido lugar en nuestra producción teatral, desde sus orígenes a nuestros días. El presente trabajo da cuenta del proceso de investigación realizado y de los resultados alcanzados.

Palabras clave: música, sonido, teatro, archivo, partituras,

\section{Stage Music in the INET Archive}

\begin{abstract}
As part of a project funded by the Activar Patrimonio 2021 grant, we explored the collection of Argentina's National Institute of Theater Studies (INET) with the purpose of discovering materials across different physical supports which would allow the analysis of characteristics of sound and spectacular music in local theatrical production, from its origins to the present. This work gives an account of that research process and the achieved results.
\end{abstract}

Keywords: music, sound, theater, archive, music sheet

\section{Fundamentación: el sonido de la escena}

La música en las artes escénicas es un área que en Argentina tiene y ha tenido un profundo desarrollo profesional y estético del cual existen documentos, textos, partituras, imágenes y grabaciones que dan cuenta de ello. Muchos de estos materiales son parte del patrimonio del Instituto Nacional de Estudios de Teatro (INET). El contacto con dichos materiales resulta sumamente enriquecedor para el estudio de 
las artes escénicas en general, puesto que nos revela aspectos sonoros, acústicos, musicales y compositivos de nuestros modos de producción espectacular.

En la historia del teatro argentino, han dejado su marca compositoras y compositores con profundo conocimiento del circuito teatral y sus modos específicos de creación y producción sonora, los cuales son muy diferentes a otros ámbitos de la música. La composición musical con propósitos escénicos es un arte específico que, a nivel profesional, requiere conocimientos y aptitudes musicales, pero también, y en igual medida, dramáticas y espectaculares.

Desde las primeras producciones de la familia Podestá, las puestas de teatro de nuestro país han contado con artistas sonoros de la escena que dan cuerpo acústico a las piezas. Se trata de creadores que han compuesto músicas originales y utilizado el lenguaje sonoro de los efectos como vehículo de expresión dramática y procedimiento estético, dejando su huella en la escena nacional.

Es preciso destacar que, en Buenos Aires, el teatro se ha desarrollado a la par del tango, la poesía y los rasgos más significativos de la cultura rioplatense, por lo que se ha nutrido de sus elementos en distintos niveles. Los instrumentos musicales y géneros más distintivos de la región forman parte de los universos ficcionales icónicos de nuestro teatro y sus personajes. Desde el protagonista de Stéfano (Discépolo, 1928) al Chicho en La Nona (Cossa, 1977), la música emerge de nuestras tramas al ritmo del tango, la milonga, la zarzuela o el pericón, que han sido parte de la columna vertebral de nuestra dramaturgia y, en consecuencia, de nuestras puestas de teatro.

Por otra parte, el arte sonoro de la escena no se apoya únicamente en composiciones originales y orquestaciones espectaculares. Al leer nuestros textos, encontramos una gran cantidad de marcas sonoras que resultan imprescindibles para hacer avanzar la acción dentro del relato: teléfonos, timbres, pasos a la distancia y músicas diegéticas abundan en las didascalias y, en muchas oportunidades, sin estos sonidos sería imposible comprender la trama.

La presencia explícita de estos eventos sonoros dentro de la diégesis revela que nuestros autores escribieron desde la certeza de que era posible realizar esos efectos en una representación y que quien dirigiese la puesta sería capaz de resolver dicha necesidad sonora de la trama.

Los eventos sonoros del relato se manifiestan, así, como parte del paradigma posible y necesario del montaje teatral, y estos eventos sonoro-musicales, acústicos, amplificados y digitales son producidos por artistas sonoros de la escena, que componen músicas originales y resuelven, con procedimientos estéticos diversos, las demandas sonoras que plantea una función de teatro.

Este proyecto, busca poner atención en la tradición e historia de la música escénica como disciplina profesional en nuestro país y propiciar el análisis de los modos sonoros de producción teatral en las puestas de Argentina.

\section{Metodología: la complejidad del sonido pasado}

El sonido es una manifestación efímera que, al igual que la puesta en escena, propone cierta complejidad en el análisis a posteriori. Sin embargo, a partir del estudio comparativo de distintos materiales en diferentes soportes es posible arribar a conclusiones acerca de cómo sonaron los espectáculos del pasado y en qué condiciones acústicas. 
A partir de documentos como partituras, programas de mano, fotografías, reseñas, críticas, grabaciones de audio en cinta abierta, discos, textos dramáticos y otros formatos, resulta posible indagar en el universo sonoro de las propuestas escénicas y distinguir dentro de ese conjunto los elementos propios del universo sonoro del relato, los del universo sonoro de la representación y los del universo sonoro espectacular.

Estos ejes temáticos, que continúan líneas de investigación planteadas con anterioridad por el proyecto integral sonidoescenico.com bajo la coordinación de quien suscribe la beca y responsable del presente trabajo, surgen de identificar que los eventos sonoros y las músicas que participan en una propuesta escénica se fundan en los requerimientos del relato y su diégesis, se manifiestan en vibraciones propias del espacio físico y acústico de la representación y se consolidan como sonidos espectaculares al entrar en relación con el espectador colectivo o audiencia. (Graciosi, 2021:1-9) Por lo tanto, al investigar acerca del plano sonoro y efímero de una propuesta teatral es preciso atender a cada una de esas áreas, sus diferentes materiales, soportes y características.

\section{Archivo INET: el eco de nuestras puestas}

Cada colección del acervo del INET revela distintos datos sonoros y musicales que nos permiten trascender el tiempo y reflexionar acerca de cómo sonaban nuestros espectáculos. En los textos dramáticos se revelan marcas sonoras propias de los ambientes, músicas y efectos necesarios para el desarrollo de la trama, los cuales se encuentran de modo implícito y/o explícito tanto en parlamentos como didascalias.

En las partituras originales es posible conocer, además de las músicas, los modos de composición y orquestación de las piezas, así como algunas cualidades de la estructura espectacular, en tanto encontramos indicaciones de temas centrales, secundarios, entreactos, partes y transiciones. En estos documentos es posible también observar firmas, sellos y membretes propios de los trámites de registro y entidades de gestión que regulan la disciplina profesional. INET tiene en su archivo más de 800 partituras, organizadas en 500 cajas y catalogadas en 1996 por el investigador Martín Bosquet.

Existen también fotografías de edificios y salas teatrales que permiten consideraciones sobre la acústica y modos de representación de cada época y ambiente sonoro., Cada espacio - el circo, los carros teatro, los teatros independientes, los teatros oficiales, los teatros comunitarios o los festivales- propone un vínculo acústico singular con su audiencia que es posible evidenciar mediante imágenes.

El archivo cuenta además con una Discoteca Dramática Documental que consiste en una colección de discos de síntesis en los que pueden oírse fragmentos de obras icónicas, producidas por el INET entre 1960 y 1966, y grabadas en los estudios de Radio Nacional, por los actores que las representaron en el momento de su estreno. Estos materiales fueron posteriormente digitalizados con la colaboración del Instituto Nacional de Musicología Carlos Vega, con diseño audiovisual de Andrea Schik, responsable del Archivo Audiovisual INET. En la actualidad, algunos de estos materiales se encuentran disponibles para la consulta en línea, a través de los canales de contenidos multimediales de la institución. 


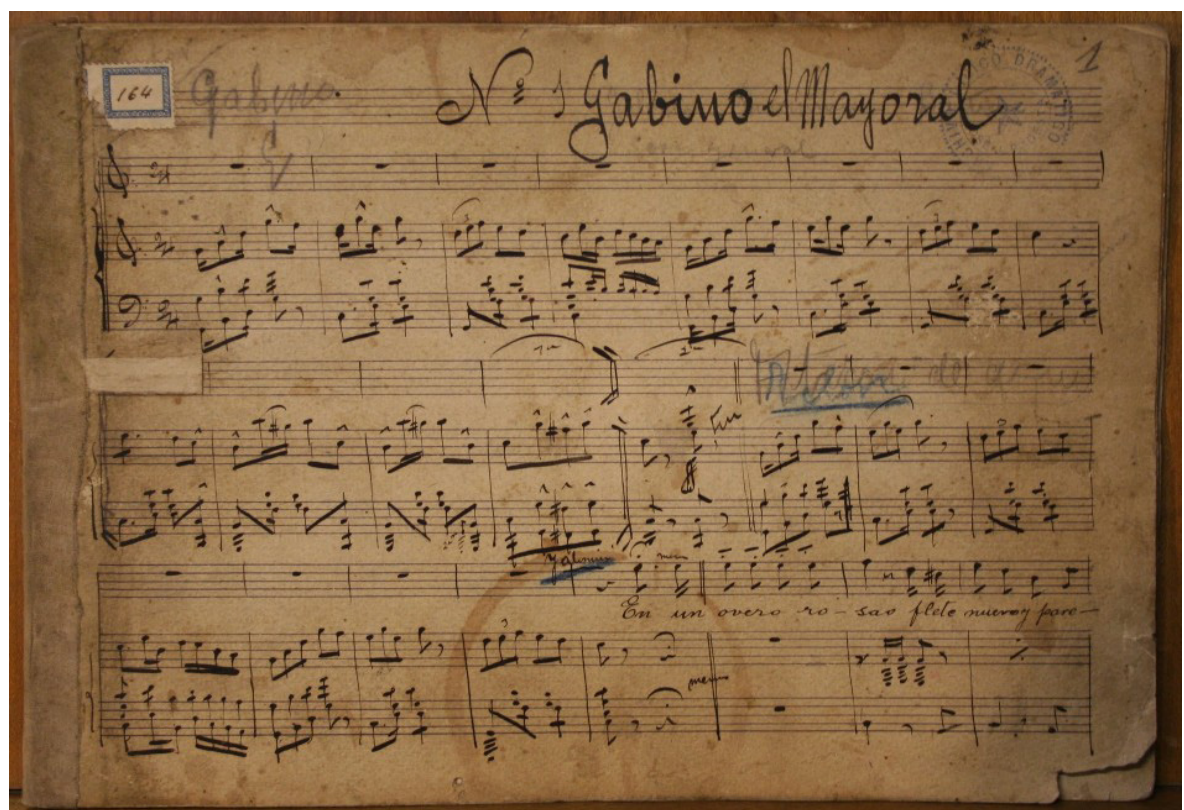

En Imagen: Gabino el Mayoral, partitura original de Eduardo García Lalanne, 1898 (Hoja 1 manuscrita) INET Caja 52obis Catalogo Bosquet 404-411. - Foto del archivo del Instituto de Estudios del Teatro.

\section{Materiales consultados para la investigación}

Las condiciones de la beca que dio lugar a esta investigación proponían diseñar proyectos de interés para la comunidad que pudiesen concretarse aún en el contexto de aislamiento sanitario causado por la pandemia del covid-19. Dado este desafío, se desarrollaron las líneas temáticas que mejor se adecuaban a los materiales de archivo ya digitalizados y disponibles de modo virtual, además de una única visita presencial a la institución.

A partir del corpus de materiales escogidos, que se detalla a continuación, se procedió a analizar el universo sonoro del relato, el universo sonoro de la representación y el universo sonoro del espectáculo de algunas piezas distinguidas de nuestra historia teatral.

\section{Partituras:}

» La piedra de escándalo. Letra: Martín Coronado, Música: Pablo Podestá - INET Tomo 40

》Triste. Aires Nacionales. Letra: Eleuterio Cueto, Música: Sara Vilar - INET Tomo 40.

" Por María. Pericón. Letra y Música: Antonio Podestá - INET Caja 265

» Varias. Antonio Podestá, el debut de la compañía y otros - INET Caja 540

»Calandria. Texto y Letra: Martiniano Leguizamón Música: Antonio Podestá - INET Caja 540

"El trigo es de Dios. Música: Lía Ciamaglia Espinosa - INET Caja 540

» Gabino el Mayoral. de Enrique García Velloso, Música Eduardo García LalanneINET Caja 520Bis

Grabaciones:

"Stéfano de Armando Discépolo - INET Discoteca Dramática Documental

" Gigoló de Enrique García Velloso - INET Discoteca Dramática Documental 


\section{Universo sonoro del relato}

Para indagar en este aspecto se analizaron los universos diegéticos de las grabaciones de Stéfano de Armando Discépolo y de Gigoló de Enrique García Velloso que integran la Discoteca Dramática Documental del archivo INET. Como punto de partida se relevaron en ambas piezas todos los eventos sonoros explícitos, ya sea mencionados en la trama o las didascalias, dando especial atención a aquellos que hacen avanzar la acción.

En relación a Stéfano es preciso señalar que Discépolo es un autor con una íntima relación con lo sonoro y musical, lo que se revela constantemente en la diégesis de sus obras. En particular, Stéfano está absolutamente atravesado por conceptos sonoros y referencias musicales, algunas de carácter explícito como que el protagonista es trombonista y alrededor de esa profesión gira el conflicto de la pieza y la construcción del grotesco. Y otras que se presentan en los parlamentos de los personajes, como por ejemplo la afirmación del protagonista "estamos en tono menor e hay que tocar lo que está escrito", que revelan un gran conocimiento y dominio de conceptos musicales por parte del autor.

En esta pieza, Discépolo plantea las tensiones entre lo vocacional y lo laboral que atraviesan quienes ejercen la música como oficio. El ideal del artista compositor contrasta con la realidad del ejecutante de profesión, que solo interpreta segundas líneas y no se luce en su carrera. A ello se suma la desgracia singular de tener un puesto en una orquesta, un empleo que no deja lugar a la expresión personal, y que además no es suficiente para sostener las necesidades económicas familiares. El artista devenido en obrero es lo que da estructura a la pieza y, de ello, surgen marcas sonoras constantes.

La pieza utiliza además la sonoridad idiomática como elemento dramático que hace referencia a una determinada pertenencia cultural. La nostalgia por la tierra de origen se revela en la oralidad y plantea un contrapunto con la música y la cultura rioplatense. Este sentimiento que se manifiesta en la sonoridad del habla es, a su vez, un vínculo con la audiencia, en una época caracterizada por una gran mayoría de descendientes de inmigrantes europeos, con quienes se establece una emoción común o conocida por la mayoría de los presentes. Es imposible pensar un universo de Discépolo silente. La expresividad del grotesco está íntimamente ligada con sonidos heredados de Europa que se amalgaman con nuestros ritmos, acentos, instrumentos y fonemas.

Por otra parte, en Gigoló de García Velloso, encontramos una serie de elementos sonoros, efectos y músicas de diversa índole que resulta pertinente enumerar: el sonido del teléfono que da inicio a la historia, funciona como elemento dramático que hace avanzar la acción y con su sonido revela una época, una clase social, una intensidad y una urgencia. Podemos apreciar también el sonido de las llaves, que brinda información del espacio y la extra escena, plantea una relación con el verosímil de la propuesta y propicia la concentración de la audiencia en la trama.

La propuesta incluye también fragmentos musicales, que dan cuenta de un planteo que tiene más que ver con el soporte radiofónico que con el teatral. Estos pasajes presentan cierto carácter narrativo en el que se expone primero un mismo tema, el cual se revisita en varias oportunidades pero, en cada una de ellas, se enfatizan distintos momentos de la frase musical: el inicio, el desarrollo o el desenlace. De este modo, se informa a la audiencia acerca del devenir del relato. Luego, al cambiar de escena y desarrollarse otro aspecto de la trama, aparece un nuevo tema musical. Este tipo de procedimiento es frecuente en propuestas de radioteatro en las que, al no haber una construcción visual del relato, el sonido y la música evidencian otros rasgos de la trama, organizan la atención e información que se brinda al oyente. Por último, 
existe un disparo de arma de fuego como efecto final, un sonido breve y potente que en su acontecer tiene el desafío de sostener un verosímil, al poder realizarse en las condiciones acústicas del espacio y soporte de la representación, sin dejar de estar a la altura de la situación dramática y espectacular. La construcción del sonido ambiente en general tiene relevancia en tanto el contrapunto entre lo rural y lo urbano aparece en el texto y propone informaciones sonoras de la diégesis. El análisis breve y general del universo sonoro de ambas piezas permite afirmar que los textos dramáticos plantean, ya desde la trama misma, informaciones sonoras precisas de las puestas teatrales de nuestra historia.

\section{Universo sonoro de la representación}

En el marco de este proyecto de investigación no fue posible acceder a materiales físicos específicos para el desarrollo de este eje temático. Dadas las restricciones sanitarias vinculadas a la pandemia y la necesidad de limitarse a los materiales disponibles de modo digital, no fue posible en esta oportunidad acceder al archivo fotográfico. Sin embargo, se cree importante comentar caminos posibles para futuras investigaciones, a partir de los materiales disponibles en el archivo INET. En fotografías de salas y espacios teatrales podríamos indagar en diferentes aspectos sonoros, acústicos, técnicos y espectaculares, como, por ejemplo:

》 Estimar la disposición espacial y la situación de escucha de la audiencia.

"Conocer la ubicación de las fuentes sonoras.

"Reconocer, en cierta medida, las condiciones acústicas y umbrales de ruido con los que se llevaron a cabo las representaciones.

" Identificar modos de representación sonora: acústica o con recursos amplificados.

» Observar tecnologías, aparatos y condiciones técnicas de los espacios de la representación.

» Reconstruir técnicas, procedimientos.

Los registros fotográficos de salas, ensayos y funciones con público son materiales que nos revelan el recipiente en el cual la vibración de la representación tuvo lugar $\mathrm{y}$, de ese registro, podemos obtener información sonora.

\section{Universo sonoro del espectáculo}

Para profundizar en este eje temático se analizó el catálogo de partituras originales del archivo INET. Estas partituras conservan las músicas de las puestas una vez montadas y estrenadas frente a un espectador colectivo o audiencia, por lo que se cree pertinente considerarlas músicas espectaculares.

Al recorrer los títulos del listado, lo primero que destaca es la cantidad de géneros musicales que dan nombre explícitamente a los espectáculos. Palabras como tango, zarzuela o milonga dan nombre a decenas de piezas. Esto revela una íntima relación entre la producción teatral argentina y algunos géneros musicales populares rioplatenses como el tango y la milonga, que conviven con reminiscencias europeas de la zarzuela o el cancan y se consolidan en manifestaciones singulares como el pericón.

Una vez en contacto con la selección de partituras escogidas para este trabajo, se observaron sus grafías particulares. Se trata de documentos manuscritos, en algunos casos escritos con lápiz en otros con tinta, en los que se pueden identificar acotaciones de sus autores, correcciones y referencias a partes del espectáculo. 
En estas partituras es posible apreciar las orquestaciones e instrumentaciones empleadas, algunas de ellas se encuentran arregladas para varias voces, en algunas se diferencian varias secciones y hasta 16 instrumentos. En la mayoría de los casos, cada folio contiene además de la partitura general, las particellas de cada intérprete.

En las indicaciones de secciones y partes se revela con claridad que la música escénica tiene características morfológicas específicas ya desde la partitura, y nos permiten reconstruir aspectos de la situación espectacular de una pieza teatral.

Además de analizar los manuscritos, se procedió a digitalizar fragmentos de materiales destacados, con el objeto de abordar el pasado también desde la experiencia audible. Oír las composiciones originales, permitió otro tipo de acercamiento con la obra, su contexto cultural y su carácter. En el marco de este proyecto se han digitalizado fragmentos de las partituras originales de La piedra de escándalo (1902) de Martín Coronado y Pablo Podestá; de Pericón por María (1900) de Antonio Podestá; de Gabino el Mayoral (1898) de Enrique García Velloso y Eduardo García Lalanne, y de Calandria (1896) de Martiniano Leguizamón y Antonio Podestá.
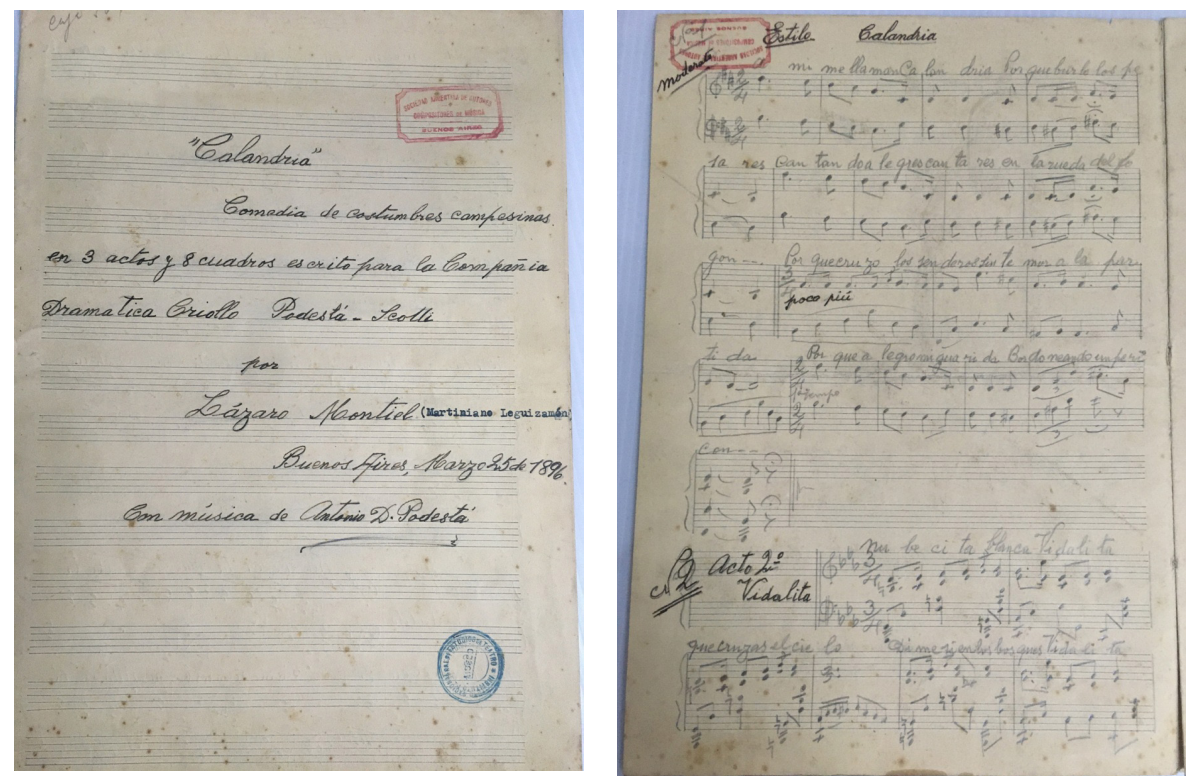

En Imagen: Calandria, partitura original de Antonio Podestá, 1896 (Carátula manuscrita y Hoja 1 manuscrita). INET Caja 504 Catálogo Bosquet 731 - Foto del archivo del Instituto de Estudios del Teatro.

\section{Resultados de la investigación}

Este proyecto habilitó un paso fundamental en el estudio de la música escénica de Argentina, disciplina de marcada presencia en la producción nacional que sin embargo carece de análisis y documentación. La investigación ha permitido plantear lineamientos generales que revelan aspectos de nuestra historia al tiempo que propician desarrollos futuros en tanto abre nuevas preguntas. ¿Cómo fue la acústica de nuestras salas? ¿Hay rasgos sonoros distintivos en la dramaturgia de cada época? A partir de los materiales del archivo INET en sus distintos soportes resultó posible reconstruir aspectos sonoros de los espectáculos del pasado, consultar partituras completas, notas, indicaciones, programas de mano y textos dramáticos, que mediante la comparación y el uso de herramientas digitales, permitieron, a su vez, reconstruir fragmentos de músicas escénicas originales y brindarlos a la comunidad para su consulta y escucha en línea. 
Se ha podido constatar mediante documentos el profundo arraigo y desarrollo que ha tenido la composición de música original con propósitos teatrales en Argentina. La producción teatral de nuestro país, fundada en carros, rancherías y lecherías, ha contado desde sus orígenes con fabricantes de rudimentos y artificios tanto de sonidos y músicas como de vestuario, escenografía, iluminación y objetos. En todas las áreas del montaje teatral, han destacado artistas mayúsculos con habilidades para afrontar las complejidades estéticas, dramáticas, prácticas y de presupuesto que presenta la disciplina y resulta necesario conocer sus oficios para conocer la historia de nuestros modos de producción.

A futuro se espera poder profundizar la investigación en los tres ejes temáticos planteados en este trabajo, digitalizar más partituras originales del catálogo, complementar con fotografías y programas de mano las secciones que no pudieron desarrollarse por las restricciones sanitarias debidas al covid-19, y fortalecer el conocimiento de la comunidad acerca de los materiales disponibles en el archivo INET que nos ponen en contacto con nuestras raíces escénico musicales y nos revelan rasgos fundamentales de nuestra herencia estética y pertenencia cultural, y fomentar así su consulta. 


\section{Bibliografía}

》Discépolo, A. (1928). Stefano, Discoteca Dramática Documental - INET https:// inet.cultura.gob.ar/noticia/discoteca-dramatica-documental/

》 García Lalanne, E (1896). Gabino El Mayoral - Partitura Digital (fragmento) - INET https://sonidoescenico.com/musicas-escenicas-en-el-archivo-inet/\#Gabinoel-Mayoral

» García Velloso, E. (1925). Gigoló, Discoteca Dramática Documental - INET https://inet.cultura.gob.ar/noticia/discoteca-dramatica-documental/

» Graciosi, M. (2014). sonidoescenico.com

" Graciosi, M. (2021). Sonido escénico. Universos sonoros de las artes escénicas y performáticas. Bs.As. MG

»Podestá, A. (1900). Pericón por María - Partitura Digital (fragmento) INET https://sonidoescenico.com/musicas-escenicas-en-el-archivoinet/\#Peric\%C3\%B3n\%20Por\%2oMar\%C3\%ADa

»Podestá, A. (1896). Calandria - Partitura Digital (fragmento) - INET https://sonidoescenico.com/musicas-escenicas-en-el-archivo-inet/\#Calandria

»Podestá, P. (1902). La piedra de escándalo - Partitura Digital (fragmento) - INET https://sonidoescenico.com/musicas-escenicas-en-el-archivo-inet/\#La-piedra-deesc\%C $3 \%$ A1ndalo 